\title{
Full-Scale Experimental Validation of Large-Eddy Simulation of Wind Flows over Complex Terrain: The Bolund Hill
}

\author{
Ashvinkumar Chaudhari, ${ }^{1}$ Antti Hellsten, ${ }^{2}$ and Jari Hämäläinen ${ }^{3}$ \\ ${ }^{1}$ CEID, School of Engineering Science, Lappeenranta University of Technology, P.O. Box 20, 53851 Lappeenranta, Finland \\ ${ }^{2}$ Finnish Meteorological Institute, P.O. Box 503, 00101 Helsinki, Finland \\ ${ }^{3}$ Lappeenranta University of Technology, P.O. Box 20, 53851 Lappeenranta, Finland
}

Correspondence should be addressed to Ashvinkumar Chaudhari; ashvinkumar.chaudhari@lut.fi

Received 29 May 2016; Accepted 5 September 2016

Academic Editor: Lucian Mihet-Popa

Copyright (C) 2016 Ashvinkumar Chaudhari et al. This is an open access article distributed under the Creative Commons Attribution License, which permits unrestricted use, distribution, and reproduction in any medium, provided the original work is properly cited.

\begin{abstract}
Numerical simulation of local atmospheric flows around a complex topography is important for many wind energy applications, as it can help in locating and optimizing wind farms. The aim of this paper is to simulate the atmospheric flows over the challenging and complex site of Bolund Hill (in Denmark) using Large-Eddy Simulations (LES) and to validate the simulation methodology against full-scale measurements. Wind prediction over a potential inland wind park is the main application of the validated LES methodology. For the first time, LES-based results from more than one wind direction of the Bolund case are reported and analyzed in detail herein. The LES results from each direction are compared with the Bolund field data in a quantitative way, for example, by using simulation error. According to the results comparison, it is found that the LES model provides by far the most accurate prediction for turbulent kinetic energy. The simulation error of this LES model for predicting turbulent kinetic energy is $19 \%$ smaller than that of all other models, whether experimental or numerical, employed previously over Bolund Hill.
\end{abstract}

\section{Introduction}

The production of wind energy is of ever-increasing interest due to risks of global warming and nuclear energy production plant accidents. Nowadays, many wind farms are being constructed in areas with complex topographies containing hills, ridges, forests, and mountains, with the intention of reaching higher wind speed. Despite the advantages, establishing a turbine over a hill presents specific difficulties, such as a considerable surge in structural loads on wind turbine blades due to inherent flow variability, large-scale unsteadiness, and flow separation, especially in complex terrains. In such terrains, the evaluation of wind resources becomes more and more challenging, and the prediction of wind-farm profitability is directly affected. Therefore, an accurate modelling of atmospheric flows over a complicated terrain has been the subject of considerable research over the past few decades. A field measurement campaign is the most accurate way to carry out wind measurements since it accounts for all environmental parameters and weather fluctuations. However, field measurements are limited to only point locations that may not provide information over the entire site. This is particularly true in the case of complex terrains. Therefore, other alternatives should be taken into account for the scale of a large wind farm. To fulfill this requirement, several numerical and experimental models are being developed to predict the wind on a larger scale. In this way, models can provide valuable information for locating and optimizing wind farms in the absence of field data. Also, models can be employed to simulate the presence of wind turbines and their interaction with the flow. However, all these modelling approaches need to be validated against fullscale measurements.

Among the numerical models, the Reynolds-averaged Navier-Stokes (RANS) approach with two-equation turbulence models has been widely used for wind prediction over complex terrains [1-9]. However, it must be mentioned that the RANS models provide solutions on the mean wind speed and the mean level of turbulent kinetic energy due to the Reynolds-averaged approach [10]. Additionally, the 
models are dependent on a number of constants which are typically calibrated for simple, canonical flows, such as turbulent channel flow [11]. Therefore, the RANS approach still has some fundamental limitations when used to predict flows with complex phenomena. For example, as pointed out by Sumner et al. [12], the RANS formulation is inherently incapable of capturing unsteady effects, such as intermittent flow separation and eddy generation and transport, and generally gives difficulties while modelling turbulence in areas of strong separation [12]. On the other hand, the LargeEddy Simulation (LES) approach resolves the large (and thus the most important) turbulent structures, and it models only the small-scale motions which are more universal than the large eddies. As a result, LES is able to capture the important unsteadiness in flows. In contrast to RANS, LES typically requires a much higher spatial resolution, resulting in substantially longer computational time [11]. However, due to rapidly increasing computer technology, the use of LES towards atmospheric flow simulation is becoming increasingly common nowadays. For wind energy applications, LES is a promising tool, as it can adequately resolve the most important eddies of the flow which are relevant to wake evolution and power production [13].

The aim of this work is to simulate atmospheric flows over a natural complex terrain and to validate the LES methodology against real measurements. Wind prediction over a potential inland wind park is the main application of the validated LES methodology. However, unlike idealized terrains [14-17], the application of LES over realistic complex topography is not so common due to several numerical challenges, such as the realistic upstream boundary condition, heterogeneous nature of surface roughness, resolving near-wall turbulence structures, and highly turbulent wind flow. Particularly, reproducing the inflow boundary condition is one of the critical challenges, as it is generally not known before a numerical simulation. Further, the inflow condition in LES must contain turbulent fluctuations as a function of space and time, with a realistic energy distribution over the spatial directions and the simulated wave-number range. In this study, the so-called recycling technique is employed for generating the instantaneous inflow boundary condition. Recently, the recycling technique was systematically studied and validated against the field measurements [18].

Several field experiments over natural terrains have been performed to provide full-scale measurements for validating flow modelling approaches. The field experiments have been carried out over Black Mountain [19], Ailsa Craig Island [20], Blashaval Hill [21], Askervein Hill [22], Kettles Hill [23], Hjardemal Escarpment [24], and so forth. Up to now, the Askervein Hill project [22] has been the most wellknown field campaign for validating numerical codes and evaluating turbulence models. In the past, several studies [3, 10, 25-28] reported successful validations of their numerical models chiefly over Askervein Hill. However, it must be mentioned that the steepness of Askervein Hill is below $20^{\circ}$, and thus it may be characterized as a smooth terrain which presents almost two-dimensional flow features [6]. Also, due to the gentle slope $\left(30^{\circ}\right)$, the Hjardemal site cannot truly be considered challenging, as the complex flow phenomena, such as flow separation, do not occur.

Recently, the Bolund field campaign [29-31] over Bolund Hill in Denmark has provided a new experimental dataset of the mean flow and the turbulence properties. In this work, to validate the LES methodology over a realistic complex terrain, we chose the challenging site of the Bolund. The hill is relatively smaller (12 $\mathrm{m}$ high) in scale than Askervein Hill, but it offers a challenging topography with steep slopes and a cliff $\left(90^{\circ}\right)$. The selection of Bolund Hill is justified by the threedimensional nature of the hill and by the flow separations induced by the cliff that make it more challenging to model than gentler terrains, such as Askervein Hill or Hjardemal Hill.

The first ever numerical and/or experimental (at laboratory scale) validation of the Bolund flows was initiated by Bechmann et al. [30] as a blind comparison of different microscale atmospheric flow models. They employed 57 models ranging from numerical to physical, including LES, RANS, and linearized models, as well as experimental models such as wind tunnel and water channel. From the blind comparison [30], they concluded that a RANS model with two-equation closure appeared to be the best model, due to the smallest simulation error for predicting the velocity speedup and turbulent kinetic energy (TKE), even compared to LES and experimental models. Such interesting feedback from the blind test is obviously encouraging for further investigation of the flow structures over the complicated Bolund site, especially by using LES model. After the blind test, there have been a number of attempts to simulate the Bolund flows by using numerical $[6,32-35]$ as well as experimental (wind-tunnel) [34, 36-38] models. However, it should be emphasized that all of the previous attempts, except the RANS simulations conducted by Prospathopoulos et al. [6], are limited to only one-wind-direction results. To our knowledge, the present work is the first LES-based study presenting and analyzing the results from more than one inflow wind direction of the Bolund case. In addition, the previous studies have focused mostly on the mean flow analysis but have not focused on the turbulence statistics in enough detail. In fact, the information on turbulence prediction is one of the important parts for a complete model validation.

In the present work, LES are carried out to investigate the atmospheric flow over the Bolund Hill, and the LES model is validated against the full scale measurement $[29,30]$. The LES-based results from two different wind directions, $270^{\circ}$ and $239^{\circ}$, are reported and analyzed in detail for both the mean and the turbulence quantities. Following Bechmann et al. [30], the results are evaluated in quantitative manner, for example, by using simulation error. The results from the two different wind directions are presented together and discussed in order to learn the differences and/or similarities that emerge owing to a change in wind direction. In the final section, using the simulation error and the model-validation criteria, this paper evaluates and compares the performance of the LES model with other models previously employed over the same hill. Through the quantitative comparison, it is found that the present LES yields the most accurate 


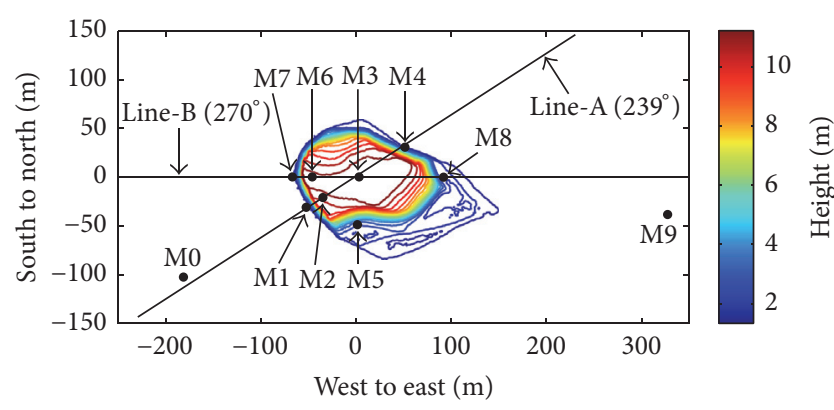

FIgURE 1: Bolund contour plot colored to illustrate the height. The black dots show the actual positions of masts (M0 to M9). The wind direction $270^{\circ}$ is from west to east.

prediction for the TKE, due to the smallest simulation error. The simulation error for the TKE increase is $19 \%$ smaller than in any other (experimental or numerical) models employed so far over the Bolund Hill.

\section{The Bolund Experiment}

Bolund Hill is a $12 \mathrm{~m}$ high, roughly $130 \mathrm{~m}$ long, and $75 \mathrm{~m}$ wide, and it is located on the north of DTU (Technical University of Denmark) in the city of Roskilde (Denmark). It is surrounded by sea, with the exception of the east side, which is connected to the mainland by a narrow isthmus. The field experiment was performed over a period of three months in 2007-2008, with the intention of providing a new full-scale dataset for validating atmospheric flow models in wind energy. Figure 1 shows the Bolund orography data with the locations of measuring masts (M0 to M9) installed on the hill during the field campaign. In this field campaign, 23 sonic and 12 cup anemometers were simultaneously employed to measure the wind velocity and variances from the 10 different masts. As it can be seen in Figure 1, the measuring masts (referred to hereafter as M1 to M8) were placed on two lines, Line-A and Line-B. In addition, two more masts, M0 and M9, were utilized to provide the inflow wind conditions for westerly and easterly winds, respectively. At each mast, the data were recorded for four different wind directions: $270^{\circ}, 255^{\circ}, 239^{\circ}$, and $90^{\circ}$. According to Berg et al. [29], the mean wind speed during the measurements was around $10 \mathrm{~m} / \mathrm{s}$, which leads to a Reynolds number Re of $10^{7}$, and, thus, the flow can be considered to be independent of the Re. Also, the field data were collected only for the neutral stability condition. In addition to offering the latest full-scale database, the Bolund field experiment also provides an interesting analysis from the blind comparison performed by Bechmann et al. [30], which allows one to analyze the validation in great detail. More detailed information about the field experiment can be found in [29-31].

\section{LES Methodology}

3.1. LES Model and the Code. In LES, the turbulent eddies larger than the grid size, which are the most energetic ones and responsible for the majority of turbulent transport, are resolved directly, whereas the eddies smaller than the grid size are more isotropic and are modelled using a subgrid scale (SGS) model. The governing equations for LES can be obtained by filtering the original continuity and NavierStokes equations. The filtered governing equations for incompressible flow can be written as

$$
\begin{gathered}
\frac{\partial \bar{u}_{i}}{\partial x_{i}}=0 \\
\frac{\partial}{\partial t}\left(\bar{u}_{i}\right)+\frac{\partial}{\partial x_{j}}\left(\bar{u}_{i} \bar{u}_{j}\right)=\nu \frac{\partial}{\partial x_{j}}\left(\frac{\partial \bar{u}_{i}}{\partial x_{j}}\right)-\frac{1}{\rho} \frac{\partial \bar{p}}{\partial x_{i}}-\frac{\partial \tau_{i j}}{\partial x_{j}},
\end{gathered}
$$

where $\bar{u}_{i}$ and $\bar{p}$ are the grid-filtered values of the velocity and the pressure, respectively, $v$ is the kinematic viscosity, $\rho$ is the fluid density, and $\tau_{i j}$ is the subgrid scale stress defined as follows:

$$
\tau_{i j}=\overline{u_{i} u_{j}}-\bar{u}_{i} \bar{u}_{j} .
$$

Since the smaller eddies are not resolved in the simulations, their effects are modelled using the one-equation eddy viscosity SGS model proposed by Yoshizawa [39]:

$$
\begin{aligned}
\frac{\partial k_{\mathrm{SGS}}}{\partial t} & +\frac{\partial}{\partial x_{j}}\left(\bar{u}_{j} k_{\mathrm{SGS}}\right) \\
= & \frac{\partial}{\partial x_{j}}\left[\left(\nu+v_{\mathrm{SGS}}\right) \frac{\partial k_{\mathrm{SGS}}}{\partial x_{j}}\right]+P_{k_{\mathrm{SGS}}}-C_{\epsilon} \frac{k_{\mathrm{SGS}}^{3 / 2}}{\Delta},
\end{aligned}
$$

where $P_{k_{\mathrm{SGS}}}=2 \nu_{\mathrm{SGS}} \bar{S}_{i j} \bar{S}_{i j}, \bar{S}_{i j}$ is the strain rate tensor, and $v_{\mathrm{SGS}}=C_{k} k_{\mathrm{SGS}}^{1 / 2} \Delta, \Delta=V^{1 / 3}$, where $V$ is the volume of the computational cell. $C_{k}=0.094$ and $C_{\epsilon}=1.048$.

In this work, the unstructured finite-volume method based code, OpenFOAM [40], is employed to solve the governing equations. The LES calculations are carried out by using our own in-house OpenFOAM-based LES solver $[18,33]$, recently implemented into OpenFOAM. The solver uses the classical fourth-order Runge-Kutta (RK4) scheme for time integration and a projection method where the velocity field is corrected using the pressure gradient inbetween the RK4 substeps. The pressure is then obtained by solving the Poisson equation. More information on the LES solver, including its validation, can be found in [18]. The oneequation model (3) is time integrated numerically using the second-order backward implicit method, and it is solved after the fourth (last) RK4 substep. All the governing equations are discretized in space using the central differencing scheme. Following the recommendations of Berg et al. [29] and Bechmann et al. [30], the present simulations do not include the effects of the Coriolis force, and the atmosphere was considered to be neutrally stratified.

3.2. Numerical Domain and Grid Resolution. Figure 2 shows the computational setup of the simulations, including an explanation of the recycling approach, and Figure 3 shows the numerical model of the hill with a surface grid. As discussed previously, the simulations use the recycling technique to generate the time-dependent inlet boundary conditions at the 


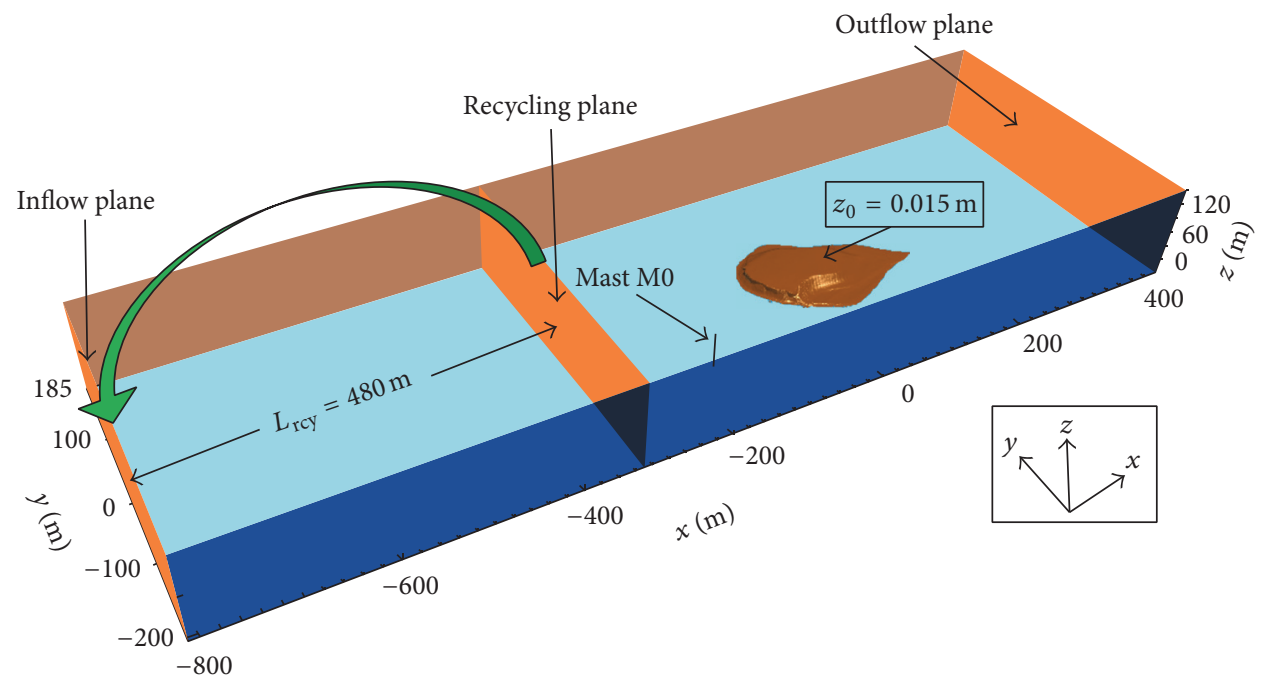

Figure 2: Picture of the computational domain with an explanation of the recycling technique used in the simulation of the $270^{\circ}$ wind direction. A similar setting is used for the $239^{\circ}$ wind direction, but with the $x$-axis aligned with that direction.

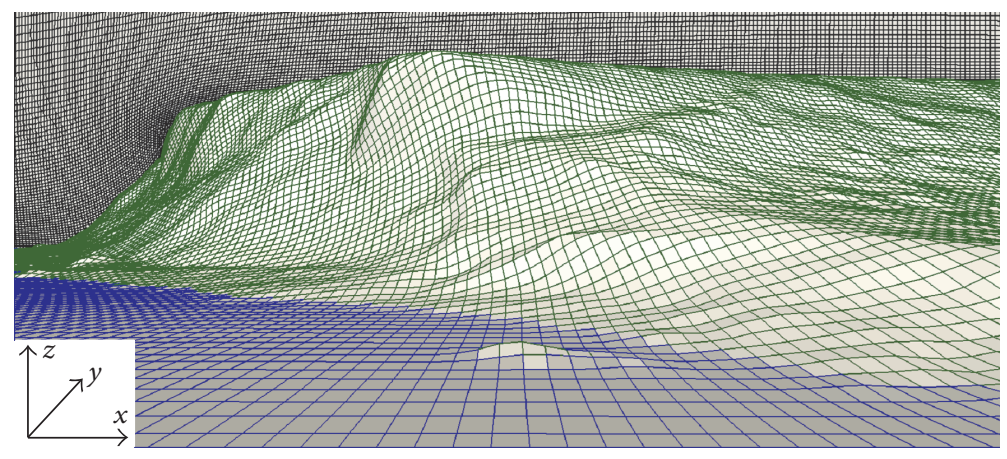

FIGURE 3: Numerical model of Bolund Hill with a surface grid.

inflow plane (see Figure 2). For this reason, the length of the computational domain must be extended on the upstream side in order to ensure the fully developed flow before the reference mast $\mathrm{M} 0$. In the stream-wise $(x)$ direction, the domain ranges from $x=-810 \mathrm{~m}$ to $400 \mathrm{~m}$. The location of the outlet boundary was followed from the previous RANS study [6]. The vertical height $(z)$ of the domain is set to $120 \mathrm{~m}$, and the boundary-layer depth $\delta$ is also $120 \mathrm{~m}$, which is approximately 10 times higher than the height of Bolund Hill $H$, that is, $\delta \approx 10 H$. The computational domain is also extended from $-205 \mathrm{~m}$ to $185 \mathrm{~m}$ in the span-wise $(y)$ direction to avoid the periodic effects on the hill part, as the periodic boundary conditions are applied in that direction. The center of the hill is located at $x=y=0$. In this way, the LES computational domain is of the size $1210 \times 390 \times 120 \mathrm{~m}^{3}$ in $x, y$, and $z$ directions, respectively.

The computational domains are then discretized using a block-structured hexahedron mesh with finer (order of $\mathrm{cm}$ ) grid resolution on the hill surface. To select the grid resolutions in the present case, some guidelines were followed from the previous work $[6,35]$ dealing with the same hill. The computational domains were meshed using the commercial grid generator called Pointwise [41]. In both LES cases, the grid created was nonisotropic with the finest grid spacing of $\Delta x=0.31 \mathrm{~m}$ and $\Delta y=0.40 \mathrm{~m}$ being kept on the vertical escarpment (see Figure 3). On the rest of the hill part, the stream-wise resolution $\Delta x$ varies from $0.31 \mathrm{~m}$ to $0.85 \mathrm{~m}$ and the span-wise $\Delta y$ from $0.40 \mathrm{~m}$ to $0.70 \mathrm{~m}$ depending on the local steepness of the hill. Outside the hill part, grid sizes in both horizontal directions are relaxed up to $4 \mathrm{~m}$ near the domain boundaries. The vertical grid spacing $\Delta z$ also varies gradually from $0.15 \mathrm{~m}$ to $4.97 \mathrm{~m}$ at the top boundary. In this way, the entire computational grid consists of $940 \times 428 \times$ $100\left(\approx 40 \times 10^{6}\right)$ hexahedron cells in each LES calculation.

3.3. Boundary Conditions. Reproducing the correct inflow velocity conditions is a challenge in LES. The inflow conditions must contain a realistic distribution of turbulence level throughout the boundary layer. Previously in several LES calculations $[10,25-27,35]$, a separate precursor simulation over a flat and homogeneous surface has been done to generate inlet conditions for complex terrain simulations. This means that the simulation must be done in two parts (for two domains or grids), and then the data from the 
TABLE 1: Mean absolute errors of speedup and TKE increase from the literature and in the present LES. The values in brackets show the best performance of the particular model type.

\begin{tabular}{|c|c|c|c|c|}
\hline Model & Mean error of $\Delta S$ (best) & Mean error of $\Delta k$ (best) & Wind direction(s) & Reference \\
\hline RANS 2 eq. & $15.1(11.4)$ & $47.0(29.9)$ & $270^{\circ}$ and $239^{\circ}$ & Bechmann et al. [30] \\
\hline RANS 1 eq. & $17.2(13.8)$ & $44.7(42.7)$ & $270^{\circ}$ and $239^{\circ}$ & Bechmann et al. [30] \\
\hline Experiment & $14.7(13.3)$ & $61.4(59.4)$ & $270^{\circ}$ and $239^{\circ}$ & Bechmann et al. [30] \\
\hline LES & $17.3(14.1)$ & $48.0(41.6)$ & $270^{\circ}$ and $239^{\circ}$ & Bechmann et al. [30] \\
\hline Linearized & $23.7(20.6)$ & $76.7(71.4)$ & $270^{\circ}$ and $239^{\circ}$ & Bechmann et al. [30] \\
\hline RANS 2 eq. & 10.3 & - & Only $270^{\circ}$ & Prospathopoulos et al. [6] \\
\hline Wind-tunnel & 12.4 & 42.2 & Only $270^{\circ}$ & Conan $[36]$ \\
\hline LES-EPFL & 9.6 & - & $270^{\circ} \& 239^{\circ}$ & Diebold et al. [35] \\
\hline Wind tunnel & 17 & 56.3 & Only $270^{\circ}$ & Yeow et al. $[37,38]$ \\
\hline Present LES & 10.3 & 24.1 & $270^{\circ}$ and $239^{\circ}$ & - \\
\hline
\end{tabular}

first (precursor) simulation is used in the second (main) simulation, that is, over complex terrain. As a consequence, the entire process (precursor and main simulations) takes a longer clock time for finalizing the simulation. Further, it requires large memory storage to store the data at each time step. Even more importantly, if one wants to make any changes in the main computational domain or grid, then the precursor simulation needs to be run again after introducing the new parameters. However, on the positive side, the precursor method may be the best option when several simulations are planned to be run using the same inflow conditions, as one can utilize the stored data in all those simulations. For the present case, the fully developed inflow boundary condition is obtained using the recycling (or mapping) method; see, for example, Chaudhari [18]. With the recycling technique, the precursor simulation is not required, and thus the entire simulation is performed in a single step; however, the user have to bear the extra CPU cost of the recycling section every time.

Using the recycling technique, the flow variables are sampled on a span-wise plane (recycling plane in Figure 2), which is sufficiently downstream of the inflow plane. Then, the sampled data are recycled back to the inflow plane at each time step, as explained in Figure 2. In this way, a recycling section is created between the inflow and the recycling planes, in which the flow becomes fully developed. Recently, Chaudhari [18] tested the suitability of the method under different recycling lengths $L_{\text {rcy, }}$, that is, the distance between the inflow and the recycling planes. It was concluded that $L_{\text {rcy }}$ should be at least three times the boundary-layer depth, that is, $L_{\text {rcy }} \geq 3 \delta$, in order to avoid artificial turbulence structures within the recycling section [18]. Hence, in this case, $L_{\text {rcy }}=480 \mathrm{~m}=4 \delta=40 H$ was used. Furthermore, the average velocity flux is fixed at the inflow boundary in order to maintain the same amount of volumetric flow throughout the simulation. The static pressure is fixed to a constant value on the outlet plane and the zero-gradient (Neumann) [40] boundary condition is used for the rest of the flow variables. The slip boundary condition is used for all the flow variables at the top boundary. The periodic boundary conditions are set in the cross-wind direction. A roughness-length $z_{0}$-based wall function is utilized to determine the ground surface fluxes on the lower boundary. The implementation and the validation of the wall function can be found from [18, 33]. Following Berg et al. [29], two types of the roughnesslength values, $z_{0}=0.0003 \mathrm{~m}$ and $0.015 \mathrm{~m}$, are used in the simulations for the water and the hill surfaces, respectively.

In this work, two LES calculations for the two inflow wind directions $\left(270^{\circ}\right.$ and $\left.239^{\circ}\right)$ are carried out. The simulations are run until the physical time of $t=2700 \mathrm{~s}$, in which all the flow quantities are time-averaged over the last $600 \mathrm{~s}$ for calculating the flow statistics. The wall-clock time for each of the calculations was about 40 days using 512 processors for simulating the physical time of $2700 \mathrm{~s}$. The calculations were carried out using Finland's most powerful supercomputer called Sisu (Cray XC30). Due to the high CPU requirement, a grid independent study of the present case is subject to large computational resources. We therefore rely on the agreement of the results (see Table 1) between the present LES and the previous numerical and experimental cases in order to evaluate the quality and the reliability of the present simulations. For the same reason (high CPU resources), the current study is based on the $10 \mathrm{~min}$ time-averaged results. However, the averaging time taken here is more than 6.5 advection times along the entire computational domain, or 32 advection times along the hill length, and importantly it is 3 times as long as that used in the previous LES by Diebold et al. [35].

\section{Results and Discussions}

We begin this section by discussing the results at the reference mast M0. After this, the LES results at the rest of the masts (M1 to M8) are presented and discussed. The results from both wind directions are discussed simultaneously in order to illuminate the differences between the results from the two directions. Finally, simulation error is calculated for both wind directions, and the errors are compared against each other as well as against the literature values.

4.1. Results from the Reference Location. Figure 4 compares the LES profiles of the mean velocity magnitude $S$ and the turbulent kinetic energy $k$ (TKE) with the field measurements at the reference location M0. The results are normalized by the frictional velocity $u_{* 0}$ at M0. Here, the mean flow profile is 


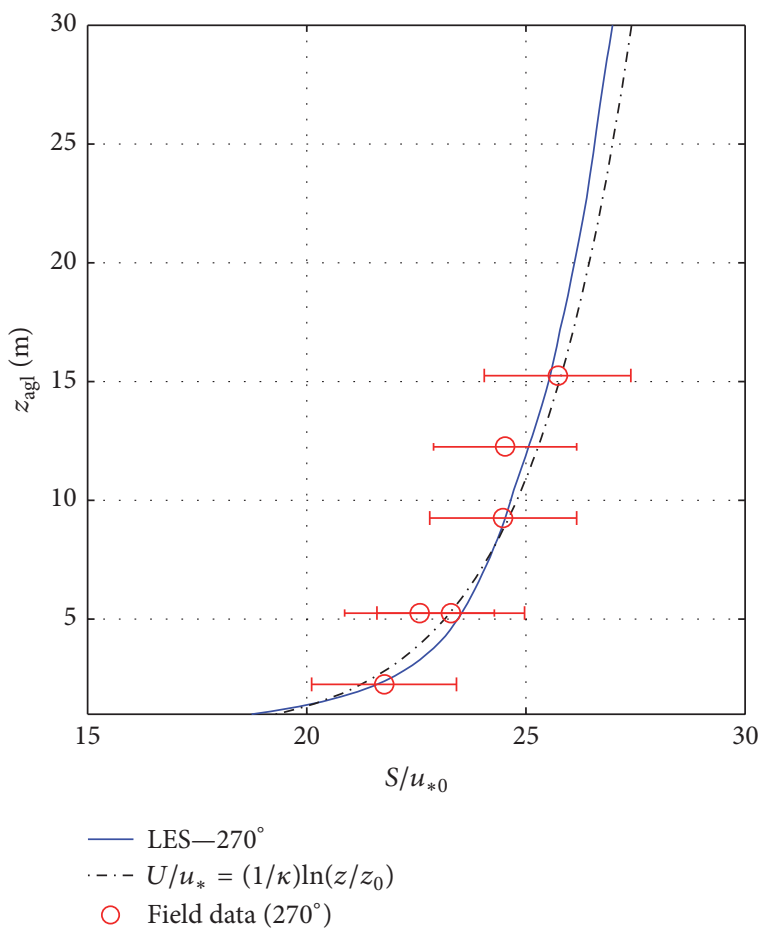

(a)

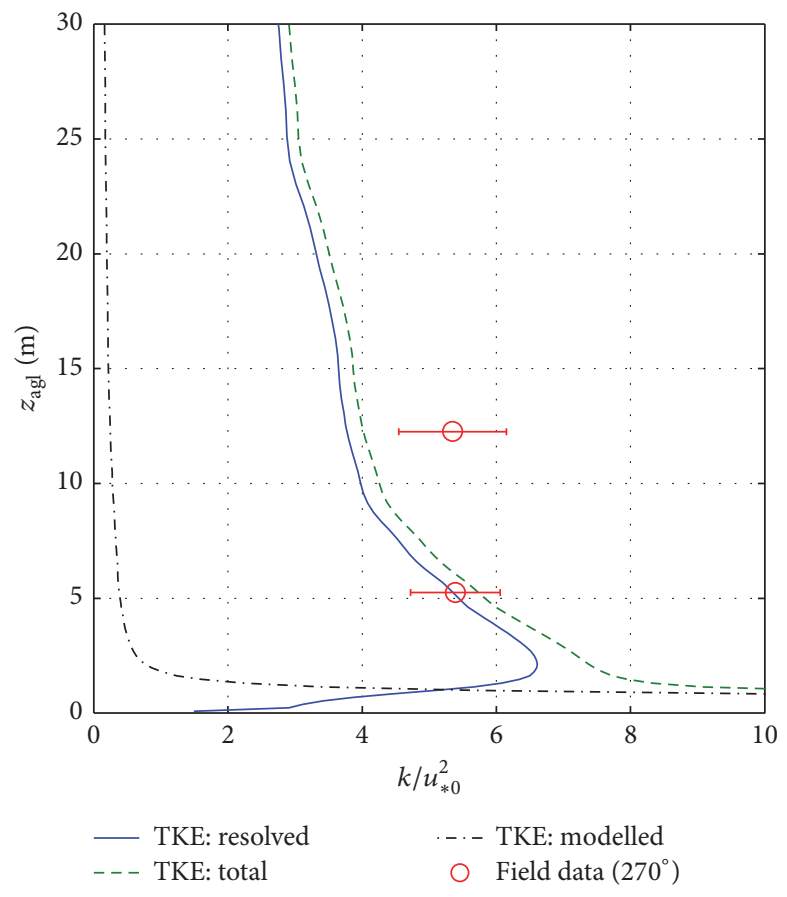

(b)

FIGURE 4: The LES profiles of the mean velocity magnitude (a) and the TKE (b) compared with the field measurements for the $270^{\circ}$ wind direction.

very well reproduced by the recycling approach, as the simulated profile agrees well with the measurements at all heights. The TKE is also well predicted by the simulation at $5 \mathrm{~m}$, but it is underestimated by about $25 \%$ at the height of $12 \mathrm{~m}$. The total (modelled and resolved) TKE also underestimates the measured TKE at $12 \mathrm{~m}$. The measurements show almost constant level of the TKE at M0, but in the simulation, the TKE decreases with height. Earlier, the LES runs submitted in the blind comparison also did not predict the constant TKE profile. This indicates that the deficiency could be very typical for LES modelling in general and thus occurs in the preset model, too. Since the modelled part of the TKE is significant in the area very close to the surface, we present the total TKE in all the results (Figures 6-13) hereafter. The error bars in the measurements show the standard deviations of the respective mean values. The standard deviation values were provided together with other statistics in the field data $[29,30]$.

4.2. Results on the Hill. Here, we first visualize the LES results on the instantaneous and mean flow structures around the hill. Figure 5 depicts the instantaneous velocity fields as well as the 10-min time-averaged ones. It can clearly be seen that the local flow field is strongly affected by the hill. In particular, the cliff is noted to enhance the turbulent fluctuations. The complexity occurring in the flow due to the cliff is also illustrated by the streamlines which highlight the mean (10-min) flow patterns around the hill (Figure 5(b)). As expected, the flow is found to be separated at several places just after the cliff as well as on the lee sides. Particularly, the cliff is forming the small zone of the reversed flow, near the ground and along the entire cliff. Masts M2 and M6 are highly influenced with this reversed flow. However, the previous studies [6, 35] including those wind tunnels [34, 36-38] did not predict this flow separation nearby the cliff.

Next, the results comparison between the simulation and the field data at different heights of all 10 masts (total 37-38 locations) is discussed. In order to see the correlation of the results, the scatter plots of all the available field data against the LES predictions for the mean velocity magnitude and the TKE are shown in Figures 6(a) and 6(b), respectively. In the plots, an error interval of $\pm 10 \%$ is also drawn for reference purpose. In Figure 6(a), it can be observed that $82 \%$ of the LES-predicted mean velocity in the case of $270^{\circ}$ is within the interval of $\pm 10 \%$. The velocity prediction is almost the same, $81 \%$, in the case of $239^{\circ}$. However, a very small deviation (about 9\%) is observed between the two cases when examining the turbulence part. For the TKE, 92\% and $83 \%$ of the predictions appear within the interval $( \pm 10 \%)$ in the cases of $270^{\circ}$ and $239^{\circ}$, respectively. When one considers the interval of $\pm 5 \%$, the TKE prediction is still good, $80 \%$, in both wind directions.

To describe the discrepancies between the simulations and the measurements in detail, more scatter plots on the velocity and TKE predictions are presented in Figures 7 and 8 , respectively. In these figures, the results are sorted with respect to the measurement height above the ground level $z_{\text {agl }}$ (Figures $7(\mathrm{a})$ and $8(\mathrm{a})$ ) and with respect to the masts (Figures $7(\mathrm{~b})$ and $8(\mathrm{~b})$ ). The locations of the masts can be 


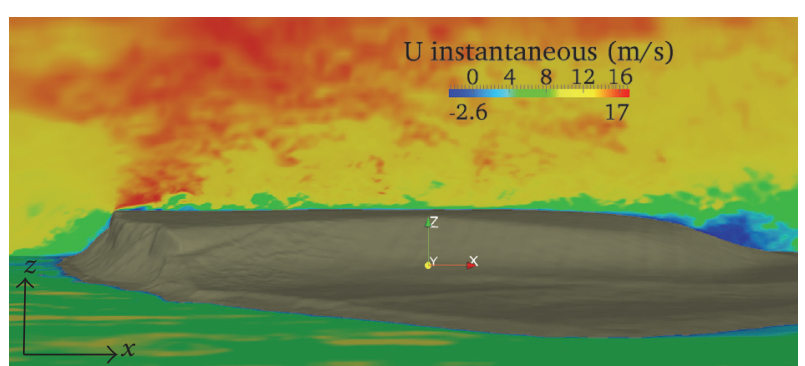

(a)

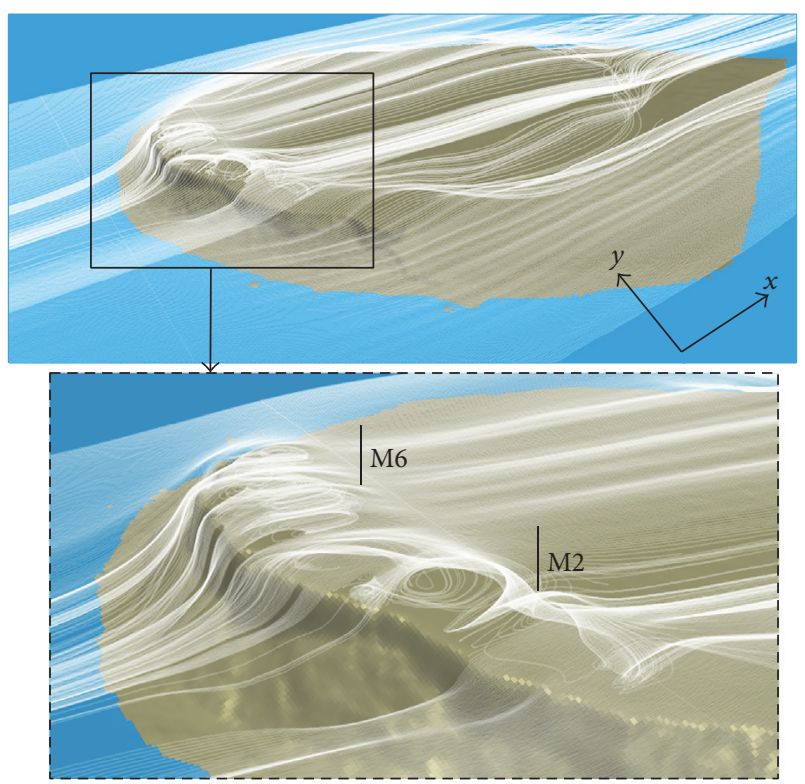

(b)

FIGURE 5: LES-predicted instantaneous stream-wise velocity fields on the vertical plane (a), and the 10 min time-averaged streamlines along the hill (b). The results are from the $270^{\circ}$ wind direction.

found from Figure 1. According to Figure 7(a), the predicted mean velocity is scattered for the height below $2 \mathrm{~m}$, reaching a maximum error of almost $128 \%$ at M2 in the case of $270^{\circ}$. On the other hand, the largest error (at $2 \mathrm{~m}$ ) is smaller by about $35 \%$ in the case of $239^{\circ}$. Generally, in both cases at $z_{\mathrm{agl}}=2$, masts M2, M6, and M8 have larger errors than the rest of the masts, as can also be seen in Figure 7(b). The large errors are due to the mast locations in which the flows are highly turbulent with flow separations (see Figure 5(b)). In both cases, the maximum error is reduced by about $100 \%$ within a distance of $3 \mathrm{~m}$, from $z_{\mathrm{agl}}=2 \mathrm{~m}$ to $5 \mathrm{~m}$. Above the height of $5 \mathrm{~m}$, the prediction is greatly improved, as the maximum error is only $11 \%$, while the majority of the error is below $5 \%$.

The overall prediction of the TKE is also scattered in both cases $\left(270^{\circ}\right.$ and $\left.239^{\circ}\right)$, although the level of maximum error is reduced by about $90 \%$ (Figure $8(a)$ ) as compared to that of the velocity. The largest discrepancy is again found at $\mathrm{M} 2$, which is $70 \%$ (at $3.6 \mathrm{~m}$ ) in the case of $270^{\circ}$ and $65 \%$ (at $2 \mathrm{~m}$ ) in the case of $239^{\circ}$. However, unlike the velocity, the scatter is relatively independent of the mast locations and measurement heights (Figure 8(b)). Despite having less error (as compared to velocity), the TKE prediction does not seem to be improved with the height from $2 \mathrm{~m}$ to $5 \mathrm{~m}$ (Figure 8(a)). Overall, the velocity prediction is better in the case of $239^{\circ}$, whereas the TKE prediction is better in the case of $270^{\circ}$. More quantitative comparison between the twowind-direction results is presented in Section 4.3.

Following Bechmann et al. [30], the numerical results are further analyzed in terms of velocity speedup $\Delta S$ and TKE increase $\Delta k$. The speedup and the TKE increase are defined as follows [30]:

$$
\begin{gathered}
\Delta S=\frac{(S)_{z_{\mathrm{agl}}}-\left(S_{0}\right)_{z_{\mathrm{agl}}},}{\left(S_{0}\right)_{z_{\mathrm{agl}}}} \\
\Delta k=\left(\frac{k}{S_{0}^{2}}\right)_{z_{\mathrm{agl}}}-\left(\frac{k_{0}}{S_{0}^{2}}\right)_{z_{\mathrm{agl}}},
\end{gathered}
$$

where the subscript 0 indicates the values $\left(S_{0}\right.$ or $\left.k_{0}\right)$ from the reference mast M0. Vertical profiles of the speedup and the TKE increase at all the masts are shown in Figures 9 and 10, respectively.

Here, it can be observed that the LES prediction of the speedup is generally acceptable (error less than $10 \%$; Figure 11(a)) at most (70\%) of the places for both wind directions. Nevertheless, for the $270^{\circ}$ wind, the simulation overestimates the measurements at the lowest heights of $\mathrm{M} 2$, M5, and M6, while it underestimates them at $z_{\text {agl }}=5$ of M8. The maximum speedup error at the lowest height $(2 \mathrm{~m})$ is $53 \%$ and it decreases to $25 \%$ at $5 \mathrm{~m}$ in the case of $270^{\circ}$ wind. Concerning the lowest heights of M2, M5, and M6, the speedup is predicted better in the case of $239^{\circ}$, as the maximum error is only about $34 \%$, which is at $2 \mathrm{~m}$ height of M2 (see Figure 11(b)). We note that the vertical profiles of the predicted speedup at M5 and M6 (below $5 \mathrm{~m}$ ) differ significantly between the two directions. At the rest of the masts, there is no such a significant difference with respect to the wind direction. This means the flows in those regions (M5 and M6) are highly sensitive to the wind direction. According to the measurements, the speedup prediction in those areas is better in the case of $239^{\circ}$.

The large discrepancies between the simulations and the measurements at M2, M5, M6, and M8 are justified by the complex nature of the flows locally, that is, highly turbulent and reversing with several flow separations generated by the steepness of the hill. Particularly, masts M2 and M6 were placed about $10 \mathrm{~m}$ away from the cliff and were strongly influenced by the very small flow separation (due to the cliff) along the edge of the cliff, as it can be seen in Figure 5(b). This particular separation is indeed much challenging to be even captured by numerical simulations because of its small size and location (near the cliff). Consequently, none of the previous attempts, including the wind-tunnel tests, have predicted this flow separation. Masts M8 and M4 were located on the lee side of the hill for $270^{\circ}$ and $239^{\circ}$ winds, respectively, and were also continuously influenced by flow separations. The simulation does predict most of the flow separations there, but the depth of the flow separation is somewhat 


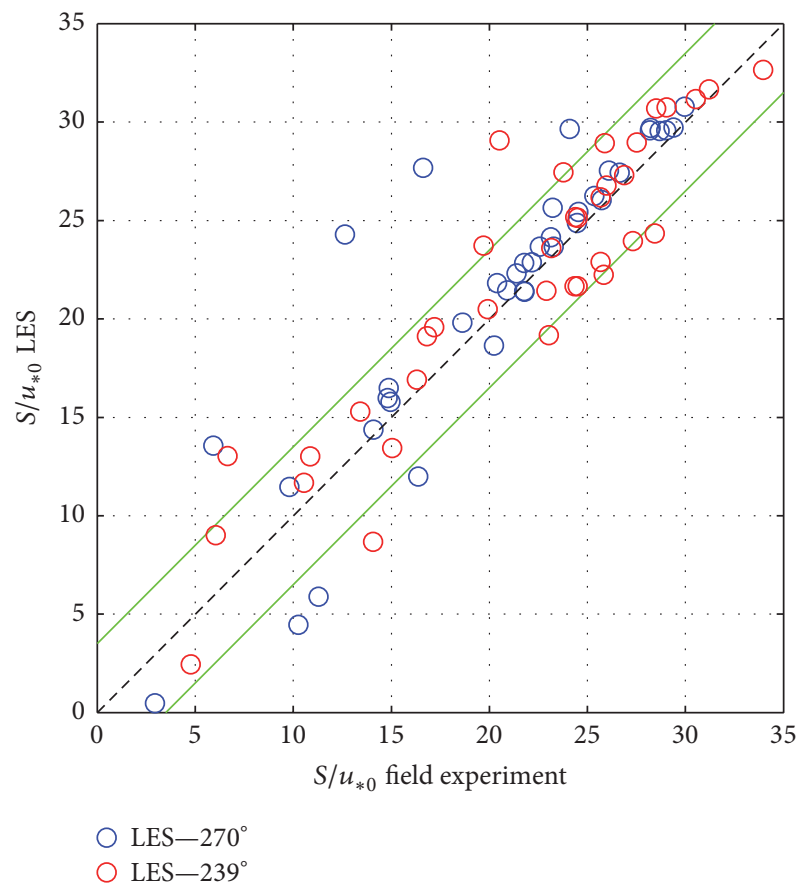

(a) Mean velocity

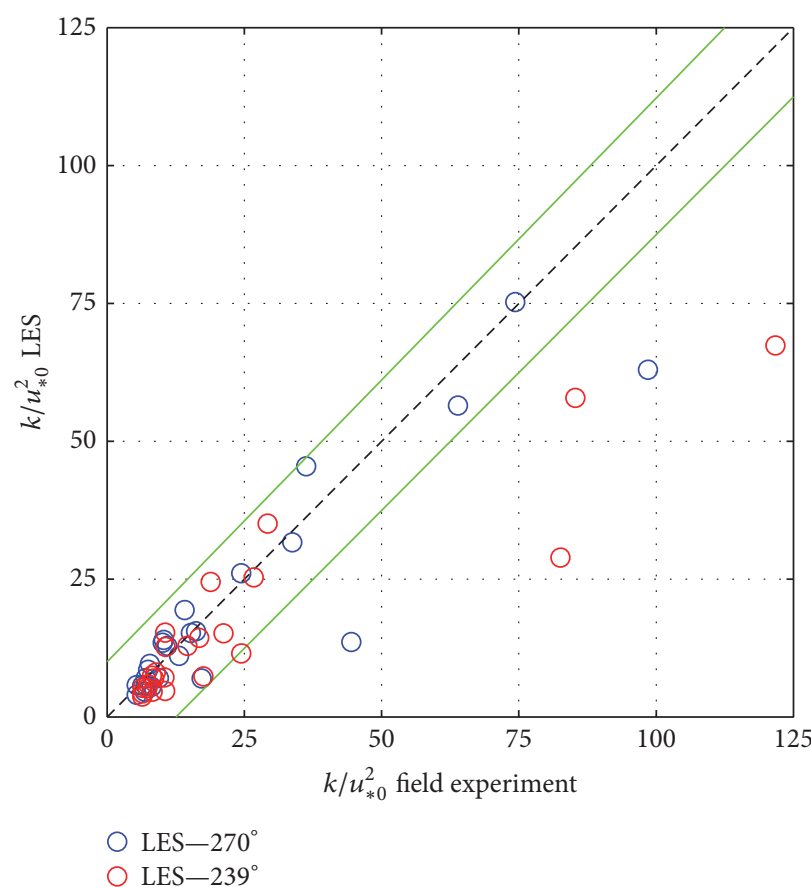

(b) TKE

FIGURE 6: Scatter plots of field data against LES results; solid lines: interval of $\pm 10 \%$ around perfect fitting (dashed line).

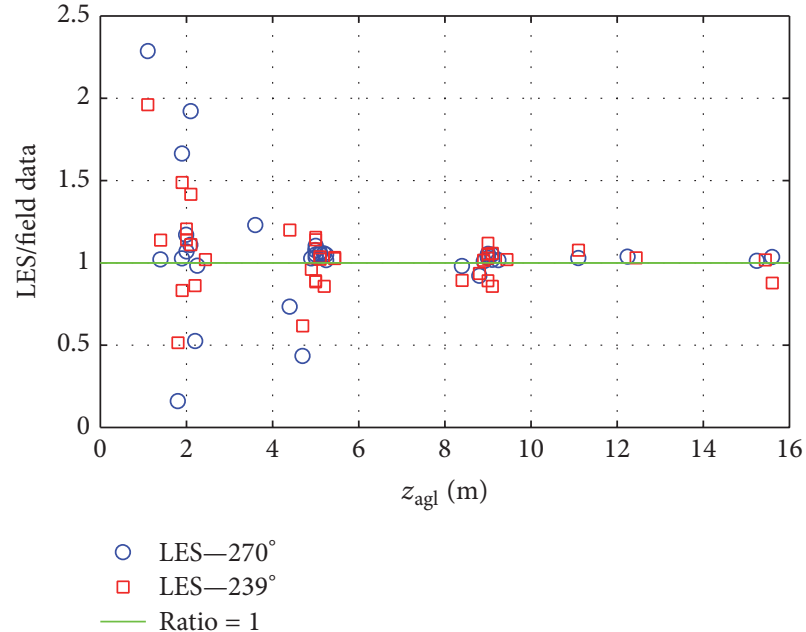

(a)

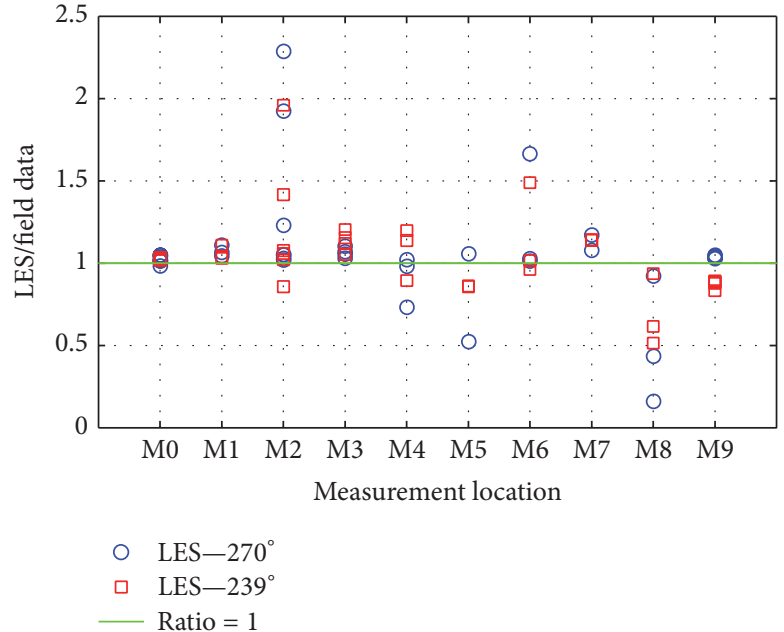

(b)

FIGURE 7: Ratio of LES to field data for the normalized velocity magnitude $S / u_{* 0}$. The results from both wind directions are sorted with respect to the height above the ground level $z_{\text {agl }}$ (a) and the mast measurement locations (b).

compromised, although more at M8 than at M4. Previous studies [6, 30, 35-38] also reported large discrepancies at several masts, except for M1 and M7.

Due to the flow separations, the turbulence level is significantly increased in a few locations. As a result, a clear peak in the TKE increase profile is visible at M2 and M6 for both winds and at M5 for the $270^{\circ}$ wind (see Figures 10(a) and 10(b)). Importantly, the simulation appears to accurately predict the extreme TKE vertical gradient, especially in the case of $270^{\circ}$, including the lower heights (Figure 10(a)), even though the velocity speedup is highly overestimated at the same locations (i.e., M2 and M6). With the exception of M2 and M6, the TKE increase is also reproduced satisfactorily in the case of $239^{\circ}$ direction. At $2 \mathrm{~m}$ height of $\mathrm{M} 2$ (for $239^{\circ}$ ), the simulation shows the largest error of $140 \%$ for predicting the TKE increase (Figure 11(b)). Most of the discrepancies between the simulation and the measurements, visible in Figures 9 and 10, and especially at M2, M6, and M8, may also 


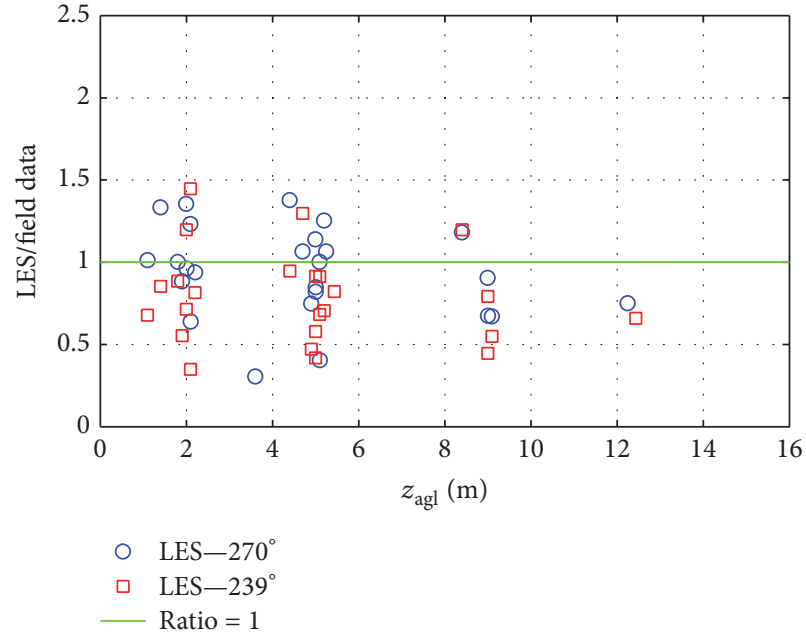

(a)

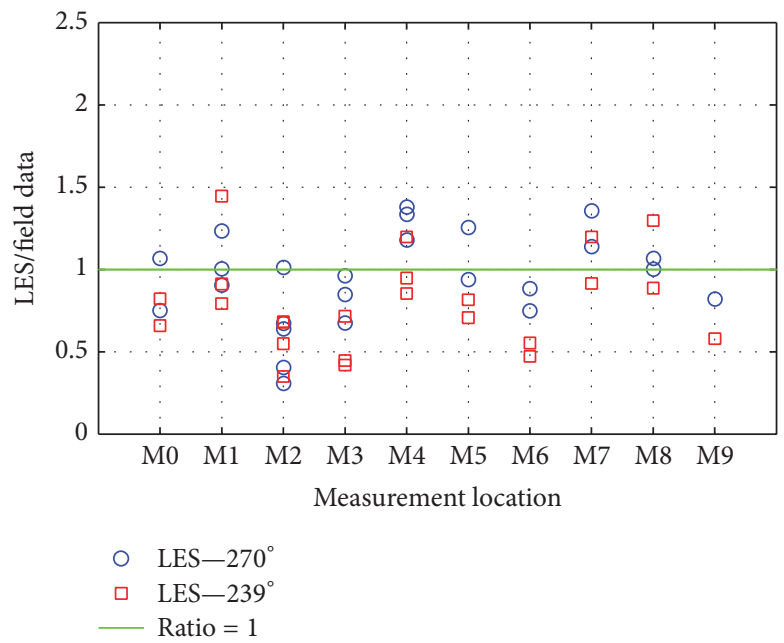

(b)

FIGURE 8: Ratio of LES to field data for the normalized TKE $k / u_{* 0}^{2}$. The results from both wind directions are sorted with respect to the height above the ground level $z_{\text {agl }}$ (a) and the mast measurement locations (b).

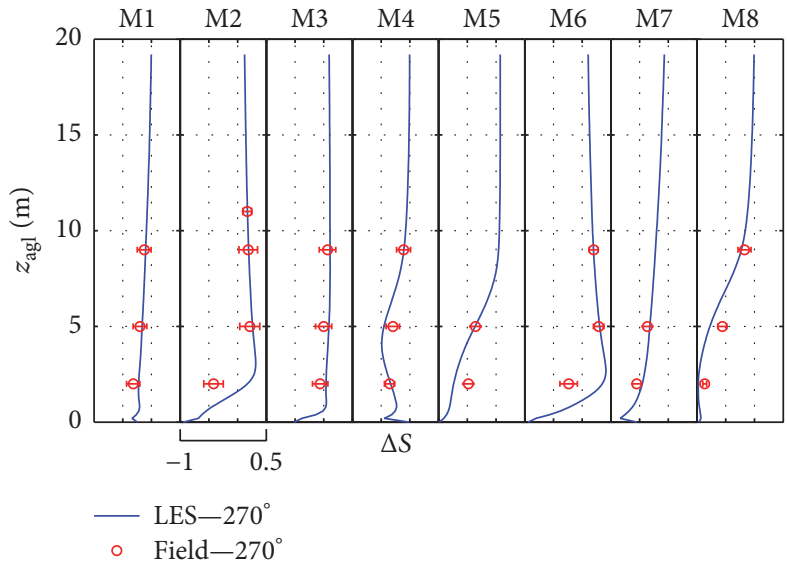

(a)

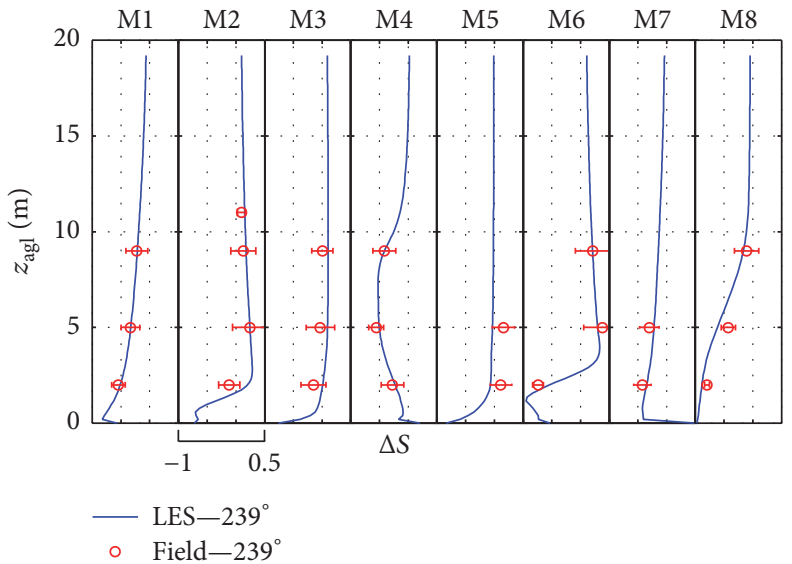

(b)

FIgURE 9: Vertical profiles of the velocity speedup $(\Delta S)$ at different masts (M1-M8) in the case of $270^{\circ}$ (a) and $239^{\circ}$ (b) wind directions.

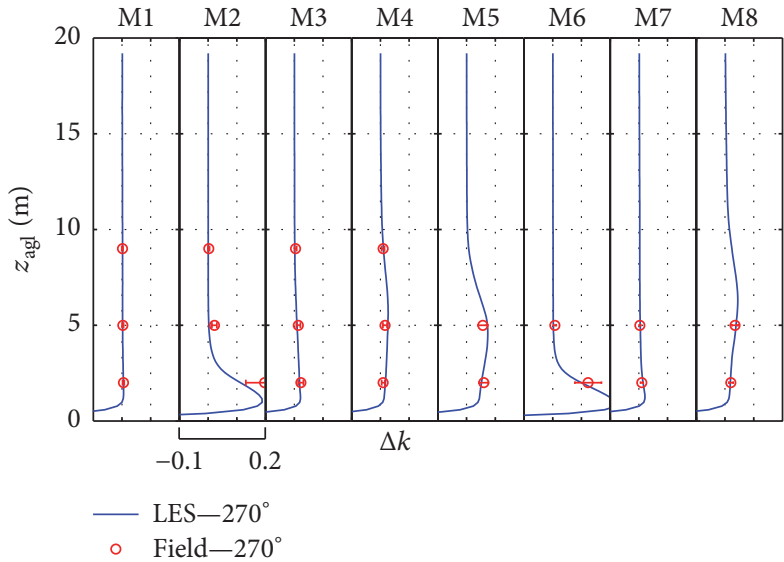

(a)

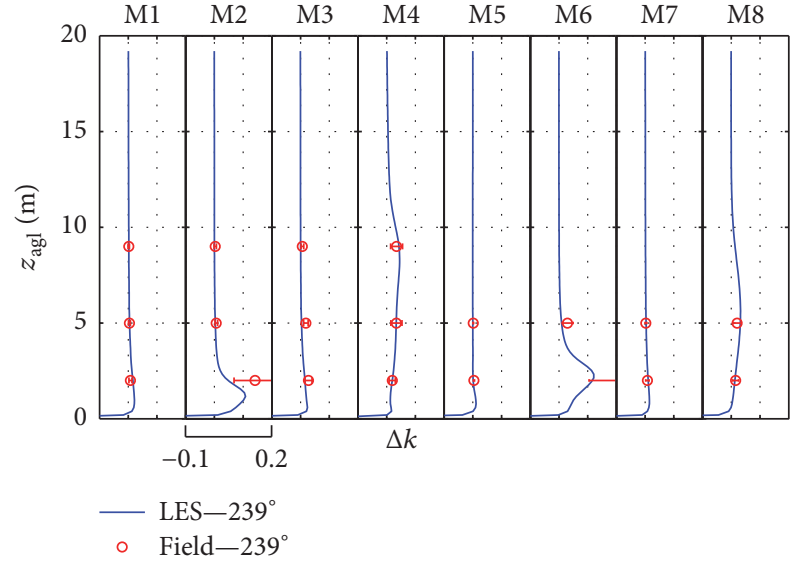

(b)

FIGURE 10: Vertical profiles of the TKE increase $(\Delta k)$ at different masts (M1-M8) in the case of $270^{\circ}$ (a) and $239^{\circ}$ (b) wind directions. 


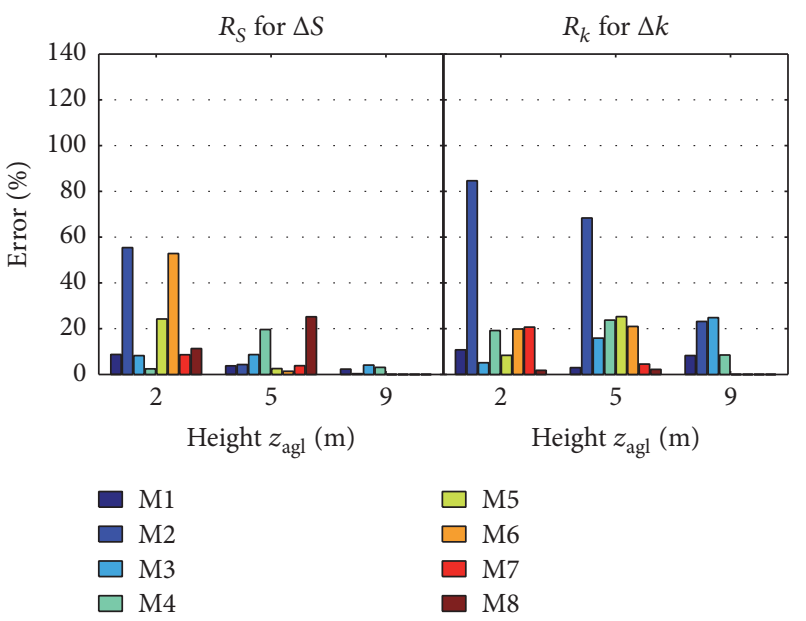

(a)

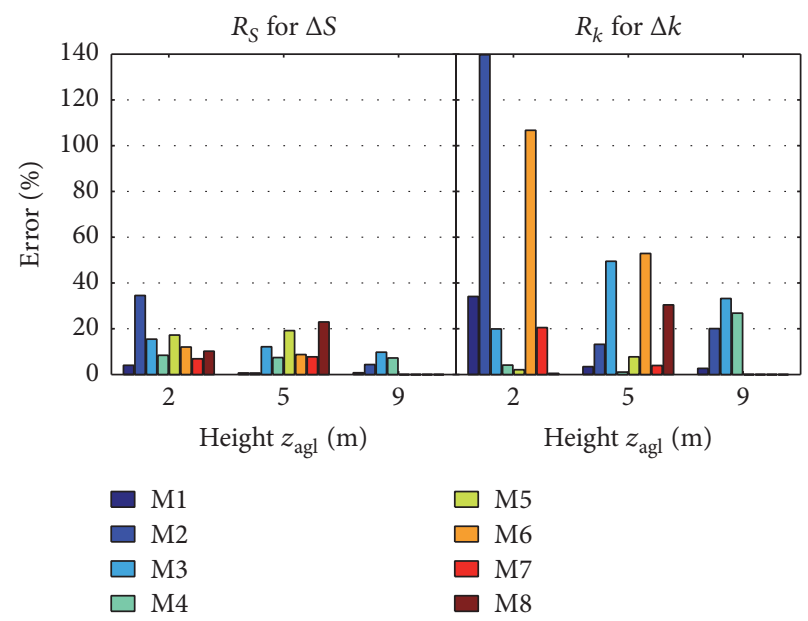

(b)

FIGURE 11: Simulation errors: $R_{S}$ for speedup and $R_{k}$ for TKE increase errors in the case of $270^{\circ}$ (a) and $239^{\circ}$ (b) wind directions.

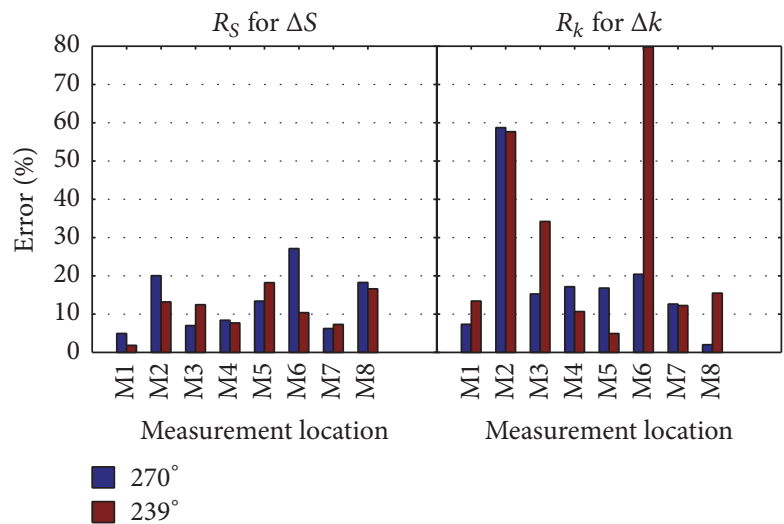

FIGURE 12: Simulation errors: $R_{S}$ for speedup and $R_{k}$ for TKE increase errors at different measurement locations. The errors $\left(R_{S}\right.$ and $R_{k}$ ) are averaged over the height for each location.

be justified by the uncertainties in the measured statistics. The high standard deviations at the lowest heights of M2 and M6 indicate high variabilities of the measured data at those places.

4.3. Simulation Error and Validation Metric. To evaluate the performance of the LES model in a quantitative way, the simulation (modelling or prediction) error from the LES results is calculated by considering the field data as a reference. Originally, Bechmann et al. [30] used the following equations to calculate the simulation errors for speedup and TKE increase. The error of the simulated speedup, $R_{S}$, is defined as follows:

$$
R_{S}=100\left(\Delta S_{s}-\Delta S_{m}\right),
$$

and the error of the simulated TKE, $R_{k}$, is

$$
R_{k}=100\left(\frac{\left(I_{s}-I_{0 s}\right)-\left(I_{m}-I_{0 m}\right)}{I_{0 m}}\right),
$$

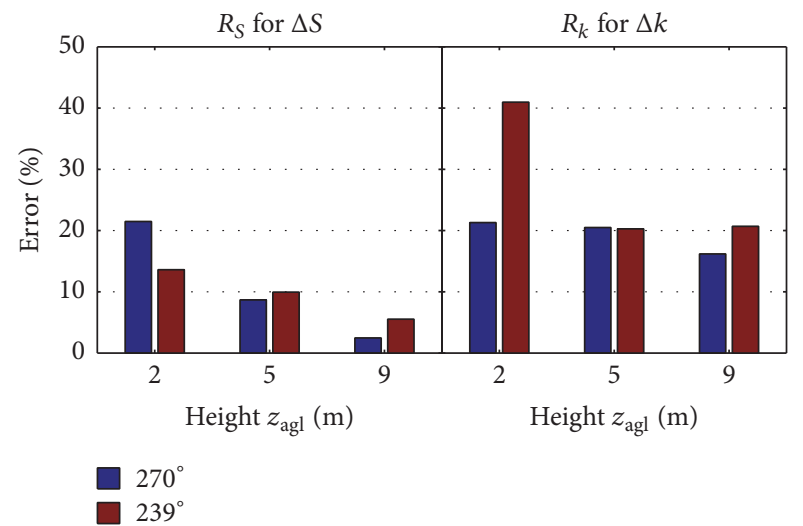

FIGURE 13: Simulation errors $R_{S}$ for speedup and $R_{k}$ for TKE increase at different measurement heights. The errors $\left(R_{S}\right.$ and $\left.R_{k}\right)$ are averaged over all the locations (masts) having the same height.

where $\Delta S$ is the speedup, $I=\sqrt{k} / S_{0}$, subscript zero denotes that the value is taken at the reference locations, and subscripts $m$ and $s$ denote the measured and simulated values, respectively. Figure 11 shows the simulation errors for the speedup and the TKE increase at each individual mast as well as at each possible height for the both wind directions. In the same way, Figure 12 displays the simulation errors, but they are averaged over the heights of each mast. The individual error from each height and/or location in Figure 11 may also be used for comparison with the results shown in the previous figures.

In the following, we turn our focus on the averaged error to discuss the results. According to Figure 12, the speedup error $R_{S}$ is less than $10 \%$ for half $(50 \%)$ of the masts in both cases. The maximum error in the case of $270^{\circ}$ is $27 \%$, which is found at M6. On the other hand, the maximum error for the $239^{\circ}$ wind is found at M5 and it is $18 \%$. For the TKE increase, the error $\left(R_{k}\right)$ is much higher than the speedup error $\left(R_{S}\right)$, reaching $59 \%$ (at M2) and $80 \%$ (at M6) in the cases of 
$270^{\circ}$ and $239^{\circ}$ winds, respectively. The high error for the TKE increase is obviously because the second-order statistic, for example, TKE or the Reynolds stress, is challenging to predict with enough accuracy as compared to mean flow (first-order statistic) in general. An interesting fact noted here is that the TKE increase error is almost the same at M2 for both winds, but a significant difference (75\%) is observed at M6 due to the change in wind direction. Despite the difficulty of predicting the TKE compared to the mean wind, the $R_{k}$ error is found to be smaller than $R_{S}$ at M6 and M8 in the case of $270^{\circ}$ and at M5 in the case of $239^{\circ}$. The high error at certain masts, such as M2 and M6, is due to their locations (near the cliff), where the aforementioned extremely complex flow behaviors occur. Indeed, virtually all previously reported models, including those wind tunnels, have failed to predict the flow accurately enough at masts M2 and M6. When excluding both M2 and M6, the averaged speedup error changes from $10.3 \%$ to $10.2 \%$, which is insignificant. However, a high reduction from 24.1\% to $13.5 \%$ is observed for the turbulence quantity. In addition, among all the masts, the standard deviation of the measured TKE is also at its highest at M2 and M6, reaching up to 24\% in the case of $239^{\circ}$, as could be expected from the error bars in Figures 9 and 10. The standard deviation or any other uncertainties of the measurements are, of course, not taken into account in the calculations of the simulation error.

Next, Figure 13 shows the (averaged) simulation error at three different heights. Here, the error is averaged over the measurement locations having the same height. For the $270^{\circ}$ wind direction, it can be seen that the errors for the speedup and for the TKE increase at the height of $2 \mathrm{~m}$ are nearly the same (21\%). This indicates that, at the lowest height, the model performs equally for both the speedup and the TKE increase. Above $2 \mathrm{~m}$, the speedup error decreases rapidly down to $2.5 \%$ at $9 \mathrm{~m}$. However, this does not happen with the TKE increase. The TKE increase error remains in the same order from $2 \mathrm{~m}$ to $5 \mathrm{~m}$, and it decreases nominally, only by $4 \%$, at $9 \mathrm{~m}$.

For the $239^{\circ}$ wind direction, the speedup error also decreases with increasing height, but not in the same trend as in the $270^{\circ}$ case. It reduces from $13.5 \%$ at $2 \mathrm{~m}$ to $5.5 \%$ at $9 \mathrm{~m}$. The TKE error is much higher, about $41 \%$ at $2 \mathrm{~m}$ (Figure 13). At this height, the TKE error is almost double compared to that of the $270^{\circ}$ case. The high error is mostly due to the poor predictions at M2 and M6. At $5 \mathrm{~m}$, the TKE error reduces greatly to $21 \%$, about the same level as in the $270^{\circ}$ case; however, it does not reduce further at $9 \mathrm{~m}$.

It should be emphasized that the measurements of the TKE at $2 \mathrm{~m}$ and $9 \mathrm{~m}$ heights of the reference location (M0) were missing in the field data (see Figure 4(b)). Therefore, by following [30], a constant value of the TKE is considered at all three heights $(2 \mathrm{~m}, 5 \mathrm{~m}$, and $9 \mathrm{~m})$ to calculate the measured TKE increase. This assumption (constant TKE with height) can highly bias the errors especially at $2 \mathrm{~m}$, as the LES results follow the height-dependent TKE values from the simulation. Moreover, it should be remembered that the flow within the surface layer, for example, $z_{\mathrm{agl}} \leq 2 \mathrm{~m}$ in the Bolund case, may be of little interest for a wind-farm developer, as one is considering the wind condition within the rotor diameter. With the average over both the wind directions, the speedup error at $5 \mathrm{~m}$ is $9.3 \%$ and is reduced to $3.9 \%$ at $9 \mathrm{~m}$. The error is not completely negligible, but the prediction could be considered accurate (less than 10\% error) [30,35].

Table 1 shows the mean errors from the two wind directions, and it compares the errors from the present case with those reported previously in the literature. The mean simulation error of the present LES is $10.3 \%$ and $24.1 \%$ for speedup and TKE increase, respectively. The LES prediction of the speedup is among the best results, as the mean speedup error from our case is only $0.7 \%$ higher than that of the best results [35]. Concerning the turbulence aspect, the present results show far smaller error in comparison with all previous results. Indeed, all prior models, except a RANS two-equation model in [30], are suffering a high TKE increase error. A couple of studies $[6,35]$ did not report the TKE increase error at all. The TKE increase error of $24.1 \%$ from this case is about $19 \%$ smaller than that of any other model. To our knowledge, this is thus the best prediction of the TKE over the Bolund Hill among all models employed over the hill so far.

Finally, the present LES model is evaluated here using three different validation metrics. First, the validation metric called the fraction of two (FAC2) shows the fraction of data that is within the interval:

$$
0.5 \leq \frac{P}{O} \leq 2,
$$

where $P$ is the predicted and $O$ is the observed value. For an ideal model prediction, one would have FAC2 $=1$ [43]. Second, the Fractional Bias (FB) can be defined as

$$
\mathrm{FB}=2 \cdot \frac{\langle O\rangle-\langle P\rangle}{\langle O\rangle+\langle P\rangle},
$$

where the angular bracket $\langle\cdot\rangle$ represents the average value over the data samples. FB indicates the relative amount of bias in the modelled results such that $\mathrm{FB}=0$ means no bias at all and FB $>0$ means systematic underestimation [44]. Finally, a third metric, known as the Normalized Mean Square Error (NMSE), is defined as follows:

$$
\text { NMSE }=\frac{\left\langle(O-P)^{2}\right\rangle}{\langle O\rangle\langle P\rangle} .
$$

NMSE is sensitive to large disagreements, in particular those occurring on the highest values [44]. The validation-metric values from the present results for both wind directions are listed in Table 2. According to the table, the present LES model passes all three validation tests, using the acceptance criteria for the model evaluation (in a rural area) proposed by Hanna and Chang [42]. In particular, the FAC2 value obtained by the present results is in general a notably high value in the evaluation of atmospheric flow models.

\section{Conclusions}

This paper has focused on simulating the atmospheric flows over natural complex terrain and on validating the LES model against full-scale measurements. Previously, several researchers utilized LES-based numerical models to validate 
TABLE 2: Calculated values of the validation metrics from the LES results. The acceptance criteria for the model evaluation are adopted from [42].

\begin{tabular}{lccc}
\hline Validation metric & Present model value & Acceptance criteria & \\
\hline FAC2 & 0.9194 & FAC2 $\geq 0.50$ & Satisfy? \\
FB & 0.1130 & $\mid$ FB $\mid \leq 0.3$ & $\checkmark$ \\
NMSE & 0.2180 & NMSE $\leq 3$ & $\checkmark$ \\
\hline
\end{tabular}

their simulations, especially over Askervein Hill, which is characterized by a smooth terrain. However, in this paper, we have selected much challenging complex terrain, the Bolund Hill, for validating the LES methodology. Unlike most of the previous studies on the Bolund case, we have carried out LES calculations for two different wind directions. The results on the mean and turbulence (e.g., TKE) quantities from the two wind directions have been analyzed equally and reported in detail herein. The results from both wind directions have been presented simultaneously and discussed quantitatively in order to learn the differences and the similarities in the results due to the change in wind direction. Using the simulation error and the model-validation criteria, the paper has evaluated and compared the performance of the LES model with other models previously employed over the hill.

The recycling method reproduced the correct mean velocity profile at the reference location (M0) but showed some difficulties in the prediction of especially constant TKE profile. Unlike the field data, the LES-predicted TKE profile decreases gradually above $z_{\text {agl }}=2.5 \mathrm{~m}$; however, it reproduced the correct (measured) value at $5 \mathrm{~m}$. Bechmann et al. [30] mentioned that all the LES models that participated in the blind test did not reproduce the correct inflow (velocity and TKE) profiles. This indicates that the reproduction of the correct inflow profiles, and especially the constant TKE, in the Bolund case is a global challenge to LES modelling in general. However, in comparison with other prior LES models $[30,35]$, the prediction of the inflow conditions is better in this study thanks to the recycling technique.

Generally speaking, the overall predictions of the speedup and the TKE increase over the hill are in close agreement with the measurements at all the positions, with the averaged difference of $10.2 \%$ for the speedup and $13.5 \%$ for the TKE increase, excluding M2 and M6. Due to the complex locations of M2 and M6, the simulation suffers from a maximum error of $140 \%$ to predict the measured values at $2 \mathrm{~m}$ height. Indeed, the measurements also show high standard deviations (up to 24\%) at the same places, and this indicates that the measured data have high variabilities at those places (M2 and M6). Above the height of $5 \mathrm{~m}$, the LES prediction of the mean flow is convincingly accurate, as the maximum difference between the simulations and the measurements is only $11 \%$. In particular, the successful prediction of the reversed flow at the escarpment edge is believed to be an excellent achievement of this particular LES model, as no other previous numerical simulations had predicted the separation. For the turbulence part, the simulation reports the best prediction of the TKE, with the averaged error of $24.1 \%$, which is $19 \%$ smaller than any other models, including the wind-tunnel experiments, reported in the past. Hence, it can be concluded that the present LES model, using the recycling technique on the inlet side, is able to reproduce the complex turbulent structures of the local wind flow over a complicated terrain such as Bolund Hill. Thus, it is possible to employ the same LES methodology to analyze the wind structures over other real terrains.

Currently, this work is being extended with the inclusion of the full depth of the atmospheric boundary layer with capping inversion and the Earth's rotation into the simulations. In the near future, the aim is to study the influence of capping inversion and the Coriolis force on the local atmospheric flows over this challenging Bolund site. The new results will then be compared with the existing results presented in this paper.

\section{Competing Interests}

The authors declare that there is no conflict of interests regarding the publication of this paper.

\section{Acknowledgments}

The computational resources for this work were provided by CSC-Finnish IT Center for Science Ltd. in Espoo, Finland. This research has been a part of the RENEWTECH Project (2011-2014), which aimed at the development of wind power technology and business in South-East Finland. The work was funded by the European Regional Development Fund (ERDF). The authors acknowledge with thanks the support of the TU1304 action "WINERCOST." The first author, A. Chaudhari, would like also to thank Lappeenranta University of Technology (LUT) for funding this research as a part of his postdoctoral research at LUT.

\section{References}

[1] A. Maurizi, J. M. L. M. Palma, and F. A. Castro, "Numerical simulation of the atmospheric flow in a mountainous region of the North of Portugal," Journal of Wind Engineering and Industrial Aerodynamics, vol. 74-76, pp. 219-228, 1998.

[2] H. G. Kim, V. C. Patel, and C. M. Lee, "Numerical simulation of wind flow over hilly terrain," Journal of Wind Engineering and Industrial Aerodynamics, vol. 87, no. 1, pp. 45-60, 2000.

[3] F. A. Castro, J. M. L. M. Palma, and A. S. Lopes, "Simulation of the Askervein flow. Part 1: Reynolds averaged Navier-Stokes equations ( $k$ - $\in$ turbulence model)," Boundary-Layer Meteorol, vol. 107, no. 3, pp. 501-530, 2003.

[4] L. M. S. Paiva, G. C. R. Bodstein, and W. F. Menezes, "Numerical simulation of atmospheric boundary layer flow over isolated and vegetated hills using RAMS," Journal of Wind Engineering 
and Industrial Aerodynamics, vol. 97, no. 9-10, pp. 439-454, 2009.

[5] A. El Kasmi and C. Masson, "Turbulence modeling of atmospheric boundary layer flow over complex terrain: a comparison of models at wind tunnel and full scale," Wind Energy, vol. 13, no. 8, pp. 689-704, 2010.

[6] J. M. Prospathopoulos, E. S. Politis, and P. K. Chaviaropoulos, "Application of a 3D RANS solver on the complex hill of Bolund and assessment of the wind flow predictions," Journal of Wind Engineering and Industrial Aerodynamics, vol. 107-108, pp. 149159, 2012.

[7] B. Blocken, A. van der Hout, J. Dekker, and O. Weiler, "CFD simulation of wind flow over natural complex terrain: case study with validation by field measurements for Ria de Ferrol, Galicia, Spain," Journal of Wind Engineering and Industrial Aerodynamics, vol. 147, pp. 43-57, 2015.

[8] L. Li, P. W. Chan, L. Zhang, and F. Hu, "Numerical simulation of a lee wave case over three-dimensional mountainous terrain under strong wind condition," Advances in Meteorology, vol. 2013, Article ID 304321, 13 pages, 2013.

[9] Y. Zheng, Y. Miao, S. Liu, B. Chen, H. Zheng, and S. Wang, "Simulating flow and dispersion by using WRF-CFD coupled model in a built-up area of Shenyang, China," Advances in Meteorology, vol. 2015, Article ID 528618, 15 pages, 2015.

[10] A. Bechmann and N. N. Sørensen, "Hybrid RANS/LES method for wind flow over complex terrain," Wind Energy, vol. 13, no. 1, pp. 36-50, 2010.

[11] S. B. Pope, Turbulent Flows, Cambridge University Press, Cambridge, UK, 2nd edition, 2000.

[12] J. Sumner, C. S. Watters, and C. Masson, "CFD in wind energy: the virtual, multiscale wind tunnel," Energies, vol. 3, no. 5, pp. 989-1013, 2010.

[13] B. Zhou and F. K. Chow, "Turbulence modeling for the stable atmospheric boundary layer and implications for wind energy," Flow, Turbulence and Combustion, vol. 88, no. 1-2, pp. 255-277, 2012.

[14] T. Allen and A. R. Brown, "Large-eddy simulation of turbulent separated flow over rough hills," Boundary-Layer Meteorology, vol. 102, no. 2, pp. 177-198, 2002.

[15] T. Tamura, S. Cao, and A. Okuno, "LES study of turbulent boundary layer over a smooth and a rough 2D hill model," Flow, Turbulence and Combustion, vol. 79, no. 4, pp. 405-432, 2007.

[16] A. Chaudhari, A. Hellsten, O. Agafonova, and J. Hämäläinen, "Large eddy simulation of boundary-layer flows over twodimensional hills," in Progress in Industrial Mathematics at ECMI 2012, M. Fontes, M. Günther, and N. Marheineke, Eds., vol. 19 of Mathematics in Industry, pp. 211-218, Springer, 2014.

[17] O. Agafonova, A. Koivuniemi, A. Chaudhari, and J. Hämäläinen, "Limits of WAsP modeling in comparison with CFD for wind flow over two-dimensional hills," in Proceedings of the European Wind Energy Association Conference (EWEA '14), Barcelona, Spain, 2014.

[18] A. Chaudhari, Large-eddy simulation of wind flows over complex terrains for wind energy applications [Ph.D. thesis], Lappeenranta University of Technology, 2014.

[19] E. F. Bradley, "An experimental study of the profiles of wind speed, shearing stress and turbulence at the crest of a large hill," Quarterly Journal of the Royal Meteorological Society, vol. 106, no. 447, pp. 101-123, 1980.

[20] G. J. Jenkins, P. J. Mason, W. H. Moores, and R. I. Sykes, "Measurements of the flow structure around Ailsa Craig, a steep three-dimensional, isolated hill," Quarterly Journalof the Royal Meteorological Society, vol. 107, no. 454, pp. 833-851, 1981.

[21] P. J. Mason and J. C. King, "Measurements and predictions of flow and turbulence over an isolated hill of moderate slope," Quarterly Journal of the Royal Meteorological Society, vol. 111, no. 468, pp. 617-640, 1985.

[22] P. A. Taylor and H. W. Teunissen, "The Askervein hill project: overview and background data," Boundary-Layer Meteorology, vol. 39, no. 1-2, pp. 15-39, 1987.

[23] J. R. Salmon, H. W. Teunissen, R. E. Mickle, and P. A. Taylor, "The Kettles hill project: field observations, wind-tunnel simulations and numerical model predictions for flow over a low hill," Boundary-Layer Meteorology, vol. 43, no. 4, pp. 309-343, 1988.

[24] S. Emeis, M. S. Courtney, J. Højstrup, and N. O. Jensen, "Hjardemaal experiment data report," Tech. Rep., Risø National Laboratory, Roskilde, Denmark, 1993.

[25] A. Bechmann, Large-eddy simulation of atmospheric flow over complex terrain [Risø-PhD thesis], Risø-PhD-28(EN), 2006.

[26] A. Silva Lopes, J. M. L. M. Palma, and F. A. Castro, "Simulation of the Askervein flow. Part 2: large-eddy simulations," Boundary-Layer Meteorology, vol. 125, no. 1, pp. 85-108, 2007.

[27] F. K. Chow and R. L. Street, "Evaluation of turbulence closure models for Large-Eddy simulation over complex terrain: flow over Askervein Hill," Journal of Applied Meteorology and Climatology, vol. 48, no. 5, pp. 1050-1065, 2009.

[28] J.-C. Golaz, J. D. Doyle, and S. Wang, "One-way nested largeeddy simulation over the Askervein hill," Journal of Advances in Modeling Earth Systems, vol. 1, no. 3, p. 6, 2009.

[29] J. Berg, J. Mann, A. Bechmann, M. S. Courtney, and H. E. Jørgensen, "The Bolund experiment, part I: flow over a steep, three-dimensional hill," Boundary-Layer Meteorology, vol. 141, no. 2, pp. 219-243, 2011.

[30] A. Bechmann, N. N. Sørensen, J. Berg, J. Mann, and P.-E. Réthoré, "The Bolund experiment, part II: blind comparison of microscale flow models," Boundary-Layer Meteorology, vol. 141, no. 2, pp. 245-271, 2011.

[31] A. Bechmann, J. Berg, M. Courtney, H. Ejsing Jørgensen, J. Mann, and N. N. Sørensen, The Bolund Experiment: Overview and Background, Danmarks Tekniske Universitet, Risø National Laboratory for Sustainable Energy, 2009.

[32] A. Chaudhari, V. Vuorinen, O. Agafonova, A. Hellsten, and J. Hämäläinen, "Large-eddy simulation for atmospheric boundary layer flows over complex terrains with applications in wind energy," in Proceedings of the 11th World Congress on Computational Mechanics (WCCM '14), 5th European Conference on Computational Mechanics (ECCM '14), and 6th European Conference on Computational Fluid Dynamics, (ECFD '14), pp. 5205-5216, Barcelona, Spain, 2014.

[33] V. Vuorinen, A. Chaudhari, and J.-P. Keskinen, "Large-eddy simulation in a complex hill terrain enabled by a compact fractional step OpenFOAM ${ }^{\circledR}$ solver," Advances in Engineering Software, vol. 79, pp. 70-80, 2015.

[34] B. Conan, A. Chaudhari, S. Aubrun, J.van Beeck, J. Hämäläinen, and A. Hellsten, "Experimental and numerical modelling of flow over complex terrain: the Bolund hill," Boundary-Layer Meteorology, vol. 158, no. 2, pp. 183-208, 2016.

[35] M. Diebold, C. Higgins, J. Fang, A. Bechmann, and M. B. Parlange, "Flow over hills: a large-eddy simulation of the Bolund case," Boundary-Layer Meteorology, vol. 148, no. 1, pp. 177-194, 2013. 
[36] B. Conan, Wind resource accessment in complex terrain by wind tunnel modelling [Ph.D. thesis], Université d'Orléans, Orléans, France, 2012.

[37] T. S. Yeow, A. Cuerva, B. Conan, and J. Pérez-Álvarez, "Wind tunnel analysis of the detachment bubble on Bolund Island," Journal of Physics: Conference Series, vol. 555, no. 1, Article ID 012021, 2014.

[38] T. S. Yeow, A. Cuerva-Tejero, and J. Pérez-Álvarez, "Reproducing the Bolund experiment in wind tunnel," Wind Energy, vol. 18, no. 1, pp. 153-169, 2015.

[39] A. Yoshizawa, "Bridging between eddy-viscosity-type and second-order models using a twoscale DIA," in Proceedings of the 9th International Symposium on Turbulent Shear Flow, vol. 3, pp. 23.1.1-23.1.6, Kyoto, Japan, 1993.

[40] OpenCFD, OpenFOAM User and Programmer's Guide, OpenFOAM Foundation, OpenCFD Ltd., 2013.

[41] Pointwise, "Pointwise: mesh \& grid generation software," http:// www.pointwise.com/.

[42] S. Hanna and J. Chang, "Acceptance criteria for urban dispersion model evaluation," Meteorology and Atmospheric Physics, vol. 116, no. 3-4, pp. 133-146, 2012.

[43] M. Schatzmann, H. R. Olesen, and J. Franke, COST 732 Model Evaluation Case Studies: Approach and Results, University of Hamburg, 2010.

[44] A. H. Maya Milliez, "Evaluation of dispersion models for improvement and guidance for the use of local-scale emergency response tools; the 'michelstadt' modelling exercisecost action es1006," in Proceedings of the 6th International Symposium on Computational Wind Engineering (CWE '14), Hamburg, Germany, 2014. 

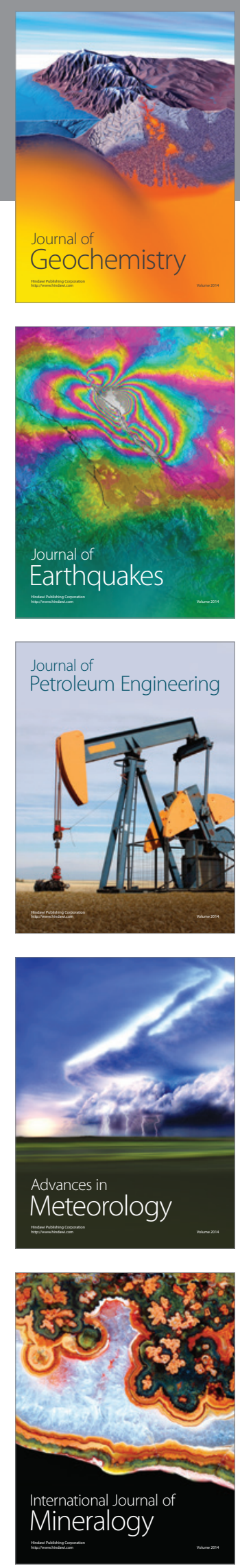
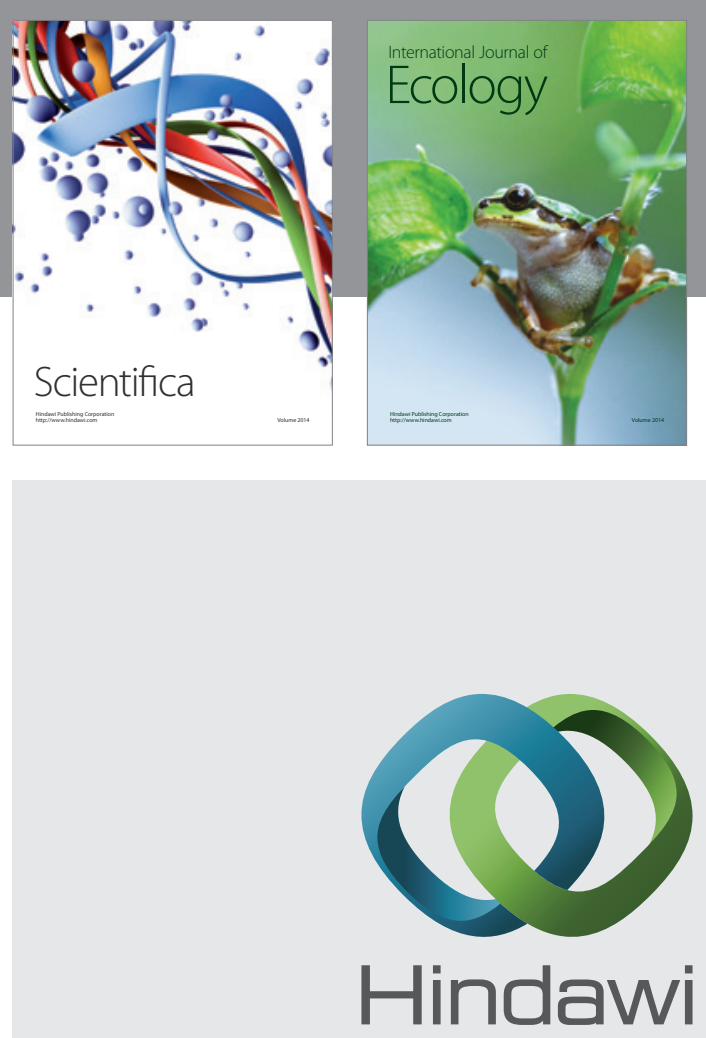

Submit your manuscripts at

http://www.hindawi.com
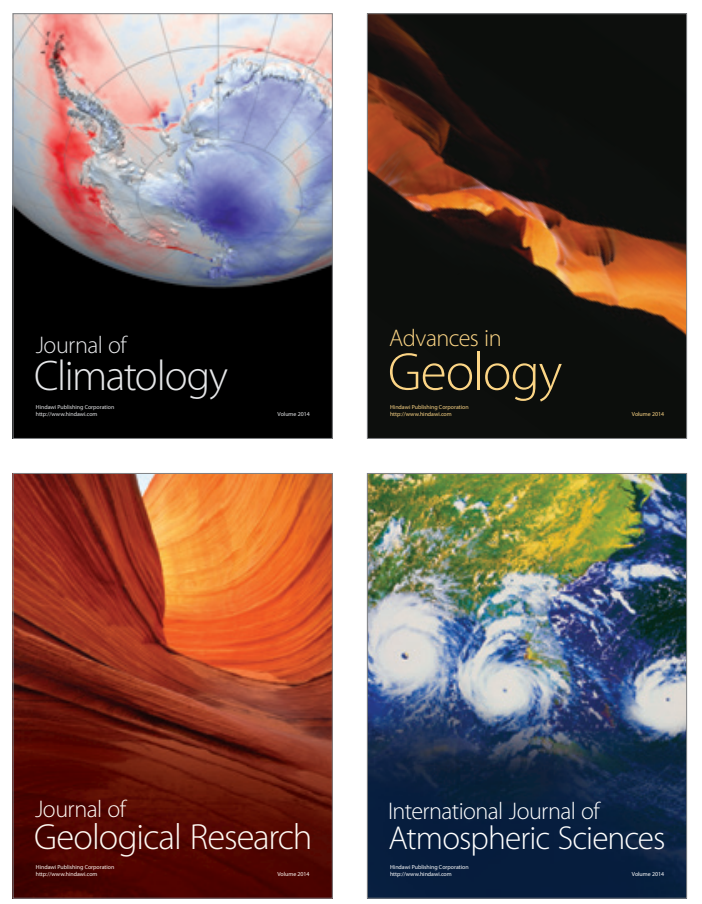

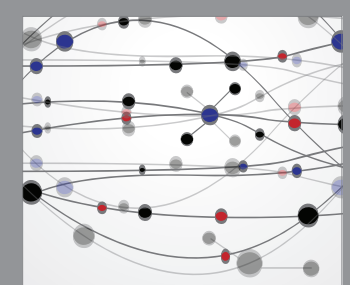

The Scientific

\section{World Journal}
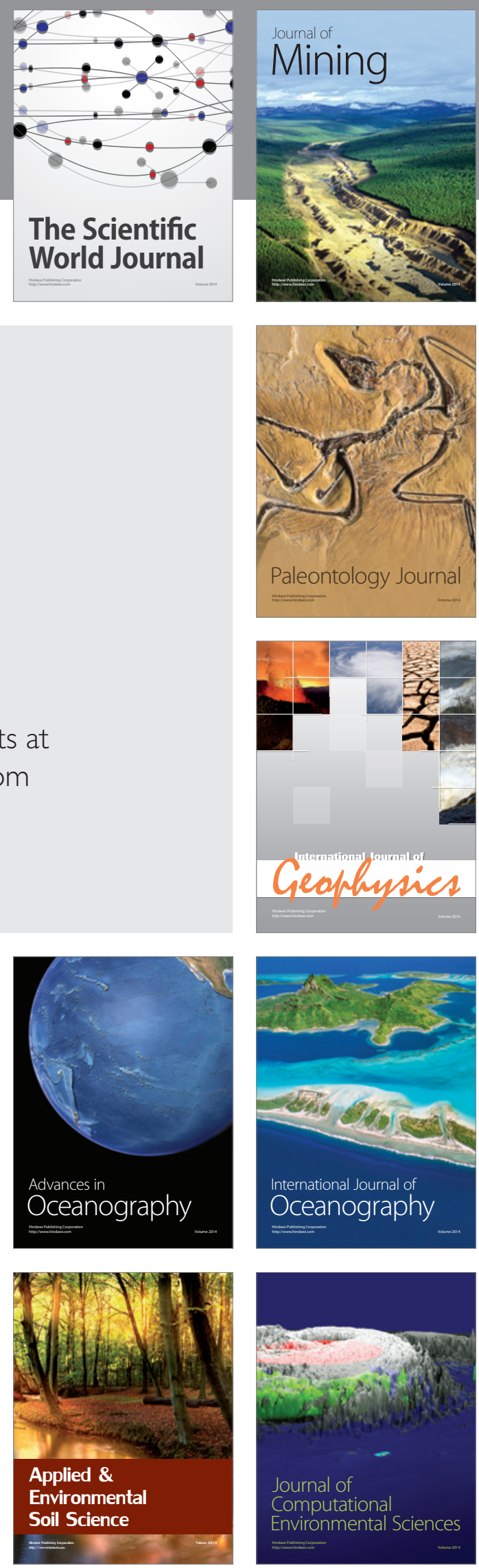